\title{
Development of Temporal Rainfall Pattern for Segamat District.
}

\author{
NOORFATHIAH CHE ALI, , , YULIARAHMADILA ERFEN ${ }^{1, b}$, \\ NURUL FAREHAH AMAT ${ }^{1, c}$ ZAWANI MOHD ZAHUDI ${ }^{1, d}$ \\ and MOHD SHALAHUDDIN ADNAN ${ }^{1, e}$
}

\author{
${ }^{1}$ Faculty of Civil Engineering and Environmental, Universiti Tun Hussein Onn Malaysia, 86400 Parit \\ Raja,Johor, Malaysia.
}

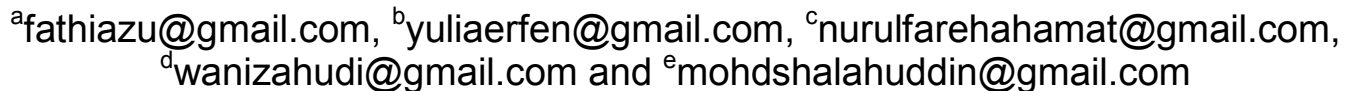

Keywords: Average Variability Method, Temporal Rainfall Pattern, Segamat.

\begin{abstract}
The designing of rainfall temporal pattern is very important in displaying the diversity and intensity of rainfall in addition to flood estimation and planning. The main purpose of this study was to develop a temporal rainfall pattern for Segamat District. Average Variability Method, AVM which had recommended by the Australian Rainfall and Runoff were used to derive design rainfall temporal patterns for this study. The survey data for 5 minute interval from 2003 to 2012 for 4 selected rainfall stations that obtained from the Drainage and Irrigation Department, DID have been selected. In this study, the temporal rainfall pattern is built for 10 minutes, 15 minutes, 30 minutes, 60 minutes, 120 minutes, 180 minutes, and 360 minutes. The results shows the actual rainfall on the field in the form of temporal rainfall pattern. Up to $75 \%$ of the temporal patterns in the region can be classified as intermediate type while the advance and delay type are $11 \%$ and $14 \%$, respectively. From the temporal rainfall pattern, the duration of rainfall occurs can be predicted, therefore, the probability of the flooding during the period can be estimated.
\end{abstract}

\section{Introduction}

A flood is commonly considered to be an unusually high stage of a river water. For a river in its natural state, occurrence of a flood usually fills up the stream to its banks and often spills over to the adjoining floodplains. For a hydraulic structure planned within the river or on an adjoining area, hence flood estimation is important and required in engineering practice for the design of the structure so as to prevent it from collapsing and causing further damage by the force of water released from design of hydraulic structure. Thus a design rainfall is required which will be later converted into the corresponding design stream flow event.

A design rainfall event is characterized by duration, average rainfall intensity of a particular Average Recurrence Interval (ARI) and temporal rainfall pattern [1]. A temporal rainfall pattern gives the proportion of total rainfall in different periods within a given rainfall duration. The national guideline of design flood estimation known as the Australian Rainfall and Runoff (ARR) [2] recommends the design event approach as the preferred method of rainfall and runoff modeling which involves the formulation of a 'design rainfall event' and use of a runoff routing model to convert the rainfall event into the stream flow event.

In Malaysia, an urban stormwater management guidelines, namely Malaysian Urban Storm Water Management Manual (MSMA) [3] which also includes guidelines for temporal rainfall pattern has published temporal rainfall pattern for Peninsular Malaysia. There are two temporal rainfall pattern are available which is for the West and East Coast of Peninsular Malaysia. Based on Hydrological Procedure No. 1 (1982) has been proposed on the temporal patterns for design to be adopted Storms in Peninsular Malaysia, the patterns were prepared for six standard durations which is $0.5,3,6,12,24$ and 72 hours [5].

This study area is located on top of the Johor State and 4 rainfall stations in the Segamat District have been selected to represent the rainfall pattern of the area. 4 stations selected for this study are Bandar Segamat station, Ladang Sungai Labis station, Air Panas station and Kemelah 
station. 10 years of rainfall data from 2003 to 2012 that obtained from the Department of Irrigation and Drainage (DID), Ampang was used. Fig.1 shows the Segamat District.

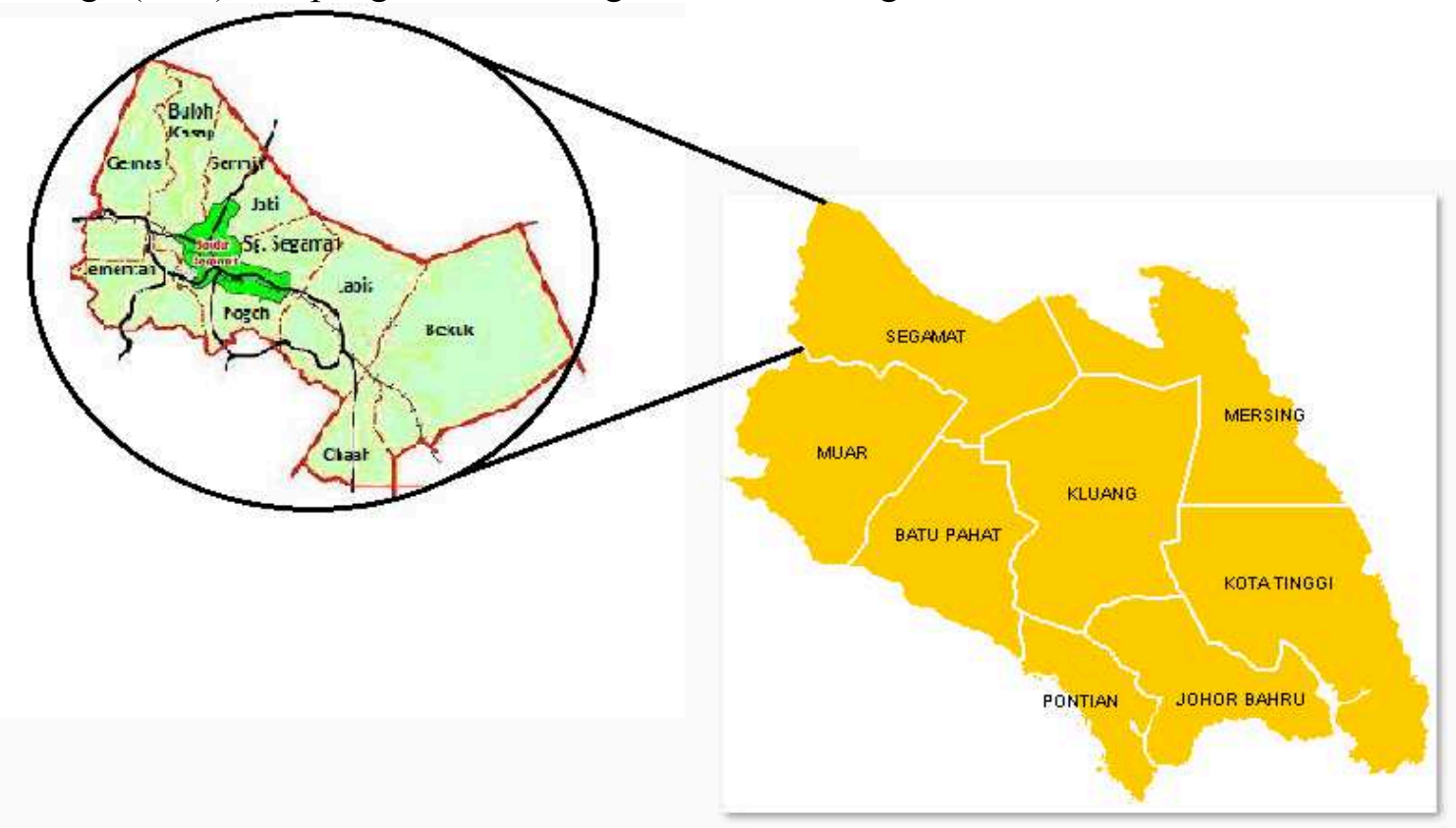

Figure 1 Segamat District in Johor State

\section{Design Temporal Rainfall Pattern}

A design rainfall temporal pattern is to represent the diversity of the intensity of the rainfall occurs during the typical storm burst. The calculation uses local rainfall data analysis of the network gauge readings. The data collection was recorded using rain gauges which are recorded on a daily basis. Time interval in minutes for reading is possible for the data used in addition to obtaining more accurate data. For this study, data obtained from the Department Of Irrigation and Drainage (DID). Average Variability Methods among method is often used in the design temporal rainfall pattern include in developing temporal rainfall pattern for Peninsular Malaysia. Based on data obtained from DID and upon recommendation of the [2], Average Variability Method found the most suitable method used for the study. Based on six standards that have been mentioned earlier, the [4] has recommended that patterns of duration of one hour or less to be based on [2] rather than [5] is more practical for long durations.

\section{Method of average variability}

The development of temporal rainfall pattern is using the average variability in the duration of the standard being proposed by [3] and[4]. According to [7], the rainfall classification is based on seven standards are also recommended in [4]. All the seven standards are 10 minutes duration, 15 minutes duration, 30 minute duration, 60 minutes duration, 120 minutes duration, 180 minutes duration and 360 minutes duration. The average variability method is explained with reference to Table 1. For example, for 15 minutes duration, 10 selected most intense bursts with dates and total rainfall amount for 5 minutes rainfall interval was listed in column 4 to 6 , the first burst is $1.2 \mathrm{~mm}$, second burst $3.6 \mathrm{~mm}$ and last is $4.1 \mathrm{~mm}$. The period then will be ranked in the next three columns 7 to 9 based on the rainfall amount from highest to lowest. For the same rainfall amount in the intervals, an average ranks are assigned.

The average value for rank of each period is obtained and are given assigned ranks based on these average values. According to [7], through this step the chronology such as heaviest rainfall periods, second heaviest periods and so on can be identified. In columns 10 to 12 , the percentages of rain in period of each rank are listed in order of magnitude, thus the average of the percentage 
will be obtained. Based on Table 1 column 10 to 12 , the average rainfall in the heaviest period is $57 \%$ of the total burst, the second heaviest $28.4 \%$ of the total burst and the third heaviest period is $14.6 \%$ of the total burst. The average percentage of amounts of rainfall are a reasonable estimate of the percentage that will occur within the burst average amounts of rainfall variability. Therefore, the chronological sequence of the periods is then determined. Where, on the assumption that the most intense rainfall should be assigned to the periods with the average rank is the lowest. The mean of the temporal rainfall pattern with averaging all of the temporal rainfall patterns for each rainfall station for each group will be determined. The final results obtained will be as temporal rainfall pattern for Segamat District.

Table 1 Analysis for 15 Minutes rainfall duration for Bandar Segamat Station

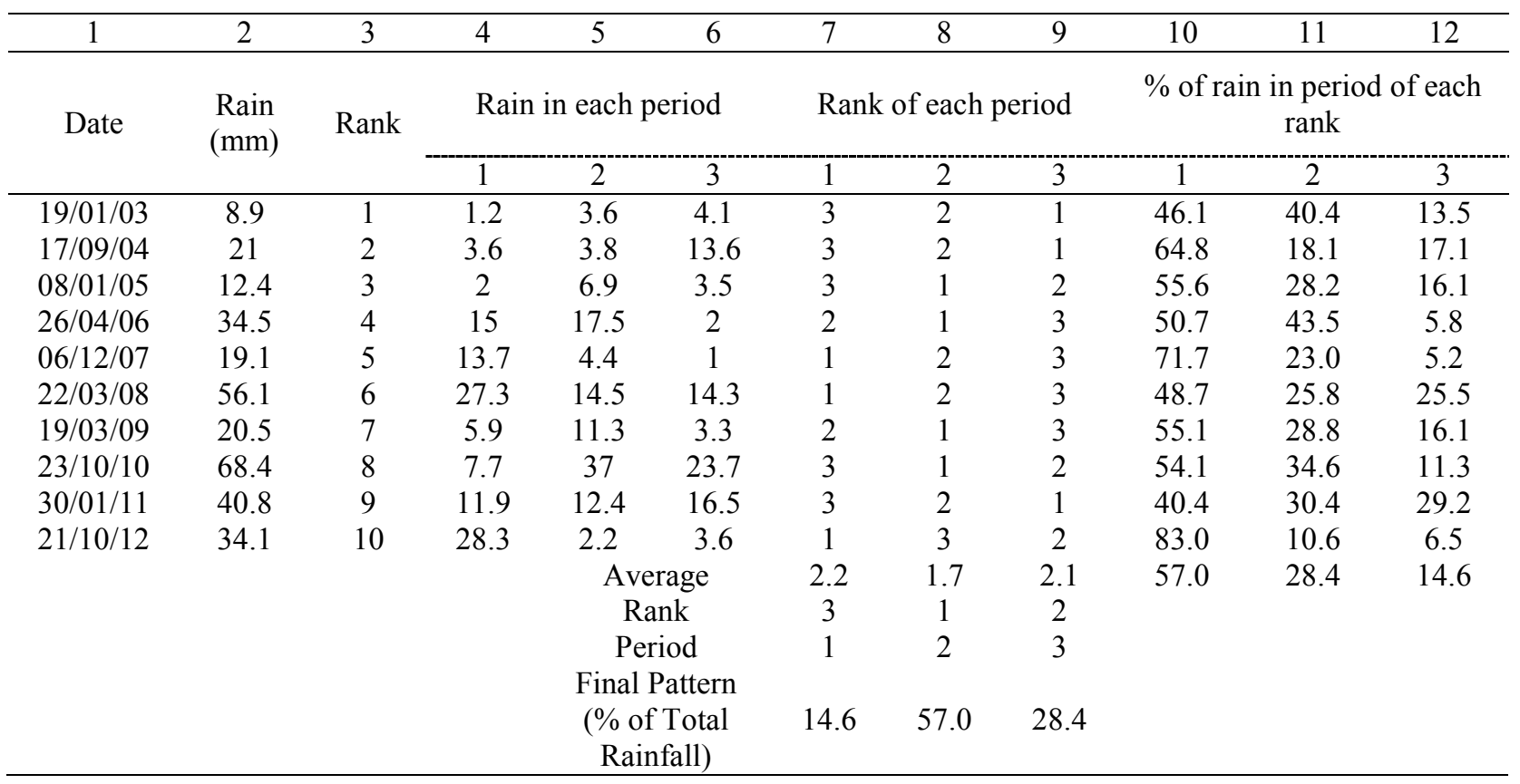

\section{Result and discussions}

After all, individual temporal rainfall patterns for each of the 4 stations were calculated and analyzed the temporal rainfall pattern then developed for Segamat District. 10 most intense rainfall data for 2003 to 2012 is taken. Each station will have seven individual temporal patterns of rainfall in the standard duration of time proposed by the [3] and [4]. With all the rainfall data obtained, thus the data were analyzed according to the procedure described previously for the Average Variability Method. Table 1 was shown an example of individual temporal rainfall pattern for the 15 minute duration of rainfall for station 2528002 in Bandar Segamat. The pattern of the 15 minutes rainfall burst of average variability derived from the 10 most intense 15 minutes duration bursts as shown would have 3 rainfall periods for every 5 minutes time interval which containing $14.6 \%, 57.0 \%$ and $28.4 \%$ of the total rainfall, respectively. While Tables 2 is a summary of the percentages of rainfall for 15 minutes rainfall for all 4 station.

Table 2 Percentage of rainfall for 15 minutes duration in each time period for individual station

\begin{tabular}{ccccccc}
\hline $\begin{array}{c}\text { Time } \\
\text { period }\end{array}$ & $\begin{array}{c}\text { Bandar } \\
\text { Segamat }\end{array}$ & Sg. Labis & Air Panas & Kemelah & Average & Fraction \\
\hline 1 & 14.6 & 34.3 & 24 & 42.3 & 28.8 & 0.288 \\
2 & 57 & 42.2 & 39.1 & 34.2 & 43.1 & 0.431 \\
3 & 28 & 23.5 & 36.9 & 23.5 & 28.0 & 0.280 \\
\hline
\end{tabular}


According to some earlier studies by [8], the needs to group according to storm events like patterns are very important. A rainfall pattern constructed for each group will be more representative of the group than one constructed using all the storms. However, a limit to the number of groups is imposed by the minimum number of storms to define a sample size [9]. The criteria used to divide the storms into six groups based on the ranking order of rainfall amounts obtained for each third of the storm duration. For this study the total individual temporal rainfall patterns produced from four rainfall stations is 28 for each of the stations and each time duration. Table 3 shows the temporal rainfall pattern for the individual station after being separated into groups.

Table 3 Temporal rainfall pattern for individual station

\begin{tabular}{|c|c|c|c|c|c|c|c|}
\hline Temporal pattern & \multicolumn{2}{|c|}{ Advanced } & \multicolumn{2}{|c|}{ Intermediate } & \multicolumn{2}{|c|}{ Delayed } & \multirow{3}{*}{ Total } \\
\hline \multirow[t]{2}{*}{ Type } & & $\square$ & & & L & & \\
\hline & A & B & $\mathrm{C}$ & $\mathrm{D}$ & $\mathrm{E}$ & $\mathrm{F}$ & \\
\hline Number of rainfall event & 3 & 0 & 7 & 14 & 0 & 4 & 28 \\
\hline Percentage of total (\%) & 11 & 0 & 25 & 50 & 0 & 14 & 100 \\
\hline Percentage by pattern (\%) & & & & & & & 100 \\
\hline
\end{tabular}

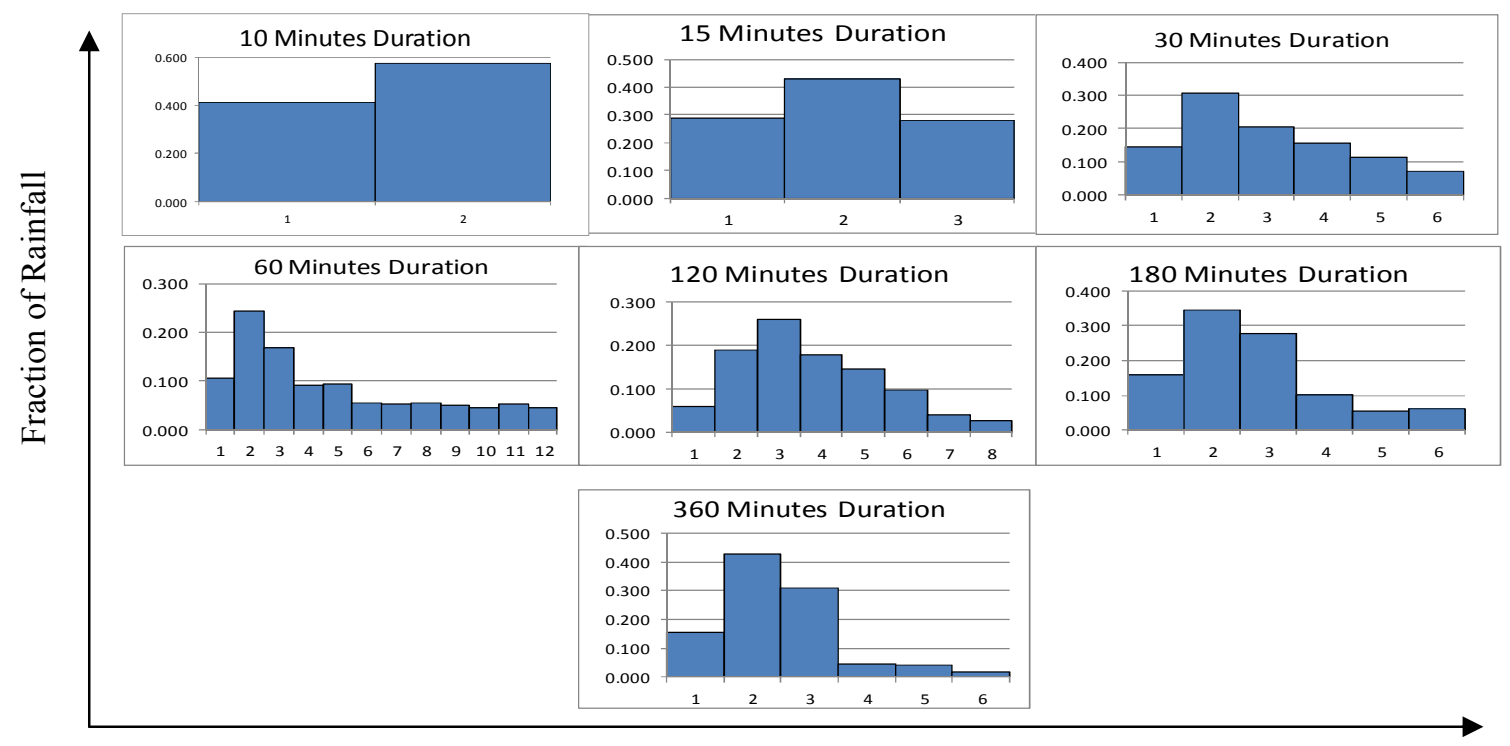

Time Period

Figure 2 Temporal Rainfall Pattern for Segamat District

While Fig. 2 is the temporal rainfall pattern in the fraction form for Segamat District, results from 28 individual temporal rainfall pattern that been produced earlier. In which a set of temporal rainfall patterns from more than one rainfall stations require mean temporal rainfall patterns to be used for a larger area that also has been practiced in [4].

\section{Conclusion}

This paper investigates the regionalization of design rainfall temporal patterns for Segamat District. Based on complete storm events, temporal patterns of data at 4 stations in Segamat District was derived for average variability method (AVM). As seen in Table 3, More than $70 \%$ of the temporal rainfall patterns in the regions are of the intermediate type (type C). Delayed type which is type E of temporal patterns were second to the largest, being $14 \%$ of all storm studied. Advanced 
types (type A) have the lowest percentage pattern with $11 \%$. It is expected that such design rainfall temporal patterns will increase the reliability of design flood estimates in hydrologic research and practice in Malaysia.

\section{References}

[1] Rahman. A, S. M. Islam, K. Rahman, S. Khan, S. Shrestha. A Windows-based Program to Derive Design Rainfall Temporal Patterns for Design Flood Estimation, Bachelor Thesis, School of Engineering and Industrial Design, University of Western Sydney, Australia, 2005.

[2] Institution of Engineers, Australia, Australian Rainfall and Runoff: A Guide to Flood Estimation'Eds Pilgrim, D.H., Barton, ACT. 1987.

[3] Department of Irrigation and Drainage Malaysia, MSMA $2^{\text {nd }}$ Edition: Urban Stormwater Management Manual for Malaysia, Malaysia, 2012.

[4] Department of Irrigation and Drainage Malaysia, Urban Stormwater Management Manual for Malaysia: Design Fundamentals, Malaysia, 2000, Vol (4).

[5]Department of Irrigation and Drainage Malaysia, Hydrological Procedure No.1: Estimation of the Design Rainstorm in Peninsular Malaysia (Revised and updated), Malaysia. 1982.

[6] Rosmina A. Bustami, Nor Azalina Rosli, Jethro Henry Adam, Kuan Pei Li, Development of Temporal Rainfall Pattern for Southern Region of Sarawak, UNIMAS E-Journal of Civil Engineering, Vol.3 (Special Issue) 2012, pp 17-23.

[7] Pilgrim, D. H., Cordery, I. and French, R., Temporal Pattern of Design Rainfall for Sydney, Institution of Engineers, Australia, Civil Eng. Trans., Vol CEII, 1969, pp 9-14.

[8] Horner, W. W., S. W. Jens, Surface Runoff Determination From Rainfall Without Using Coefficients, Trans. ASCE., Vol.107, 1942, pp 1039-1117.

[9] Chuckwuna, G. O., Rainfall Temporal Pattern and Runoff at Coshocton, Ohio, Bachelor Thesis, Ohio State University, 1982. 